\title{
Prenatal screening for congenital heart disease
}

\author{
LINDSEY D ALLAN, DIANE C CRAWFORD, SUNDER K CHITA, MICHAEL J TYNAN
}

\begin{abstract}
Routine ultrasound examination of the fetus is already established in most obstetric units in Britain. A simple method was devised to evaluate one section of the fetal heart systematically. Examination of this section, the four chamber view, may readily be incorporated into routine obstetric screening. Severe cardiac abnormalities detectable in this view occur in two per 1000 pregnancies. For six years the department of paediatric cardiology at Guy's Hospital, London, served as a referral centre for fetal echocardiography. As teaching became more widespread an increasing proportion of cases of cardiac anomaly were referred because the obstetrician suspected abnormality on examination of the four chamber view. Currently $80 \%$ of detected abnormalities are referred for this reason.

Further extension and organisation of teaching might result in most severe cardiac malformations being detected in early prenatal life.
\end{abstract}

\section{Introduction}

Congenital heart disease is now the most common severe congenital abnormality found in live births' ${ }^{1}$ and the cause of more than half the deaths from congenital anomalies in childhood. ${ }^{2}$ Ultrasound examination of the heart in prenatal and postnatal life has proved a reliable tool in the diagnosis of congenital heart disease. ${ }^{3-6}$ Despite this, evaluation of the fetal heart has not been included in routine ultrasound examination of the fetus. This may be because of the

Department of Paediatric Cardiology, Guy's Hospital, London LINDSEY D ALLAN, $\mathrm{MD}, \mathrm{MRCP}$, senior lecturer in perinatal cardiology DIANE C CRAWFORD, MSC, PHD, research assistant, perinatal cardiology unit SUNDER K CHITA, technician, perinatal cardiology unit MICHAEL J TYNAN, MD, FRCP, professor of paediatric cardiology

Correspondence and requests for reprints to: Dr L D Allan, British Heart Foundation Perinatal Cardiology Research Centre, 15th Floor, Guy's Tower, Guy's Hospital, London SE1 9RT. apparent complexity of the fetal cardiac anatomy and the multiplicity of congenital cardiac malformations. It may also be because complete evaluation of the fetal heart ${ }^{7}$ is difficult initially and cannot be carried out quickly in every patient. To address this problem we have devised a simplified approach to fetal cardiac scanning which can readily be incorporated into routine obstetric ultrasound examination from 16 weeks of gestation onwards. This will not detect all forms of congenital heart disease but will help in the diagnosis of many severe defects.

\section{Methods}

For the past six years interested obstetricians and ultrasonographers have been taught how to obtain, recognise, and interpret a single section of the fetal heart-the four chamber view. This view is achieved by a transverse section across the thorax just above the diaphragm. The section must be obtained straight across the thorax; the spine must be seen as a circle and at least one rib should be seen complete. This view was readily and quickly achieved by experienced ultrasonographers and could be included as part of a routine obstetric scan.

The four chamber view may vary slightly with the orientation of the ultrasound beam to the heart, but whatever the orientation the following features are invariably visualised and should be noted (see figure): (1) the heart occupies roughly one third of the fetal thorax; (2) the right ventricle lies closer to the anterior chest wall than the left; (3) the atria are of roughly equal size; (4) the ventricles are of roughly equal size; (5) the interventricular septum and free walls of the right and left ventricles are of similar thickness; (6) the atrioventricular valves and atrial and ventricular septa meet at the crux of the heart; and (7) the foramen ovale-the normal interatrial communication in prenatal life-is present.

Normal appearance of this single scan plane excludes most severe congenital heart disease. Conversely, an abnormality should be detectable in over two per 1000 pregnancies.

\section{Results}

Table I shows the number of cardiac abnormalities detected in the referral centre during January 1980 to October 1985. An increase in absolute numbers detected over the six years represented increased referrals of al high risk pregnancies-those in mothers with a family history of congenital 

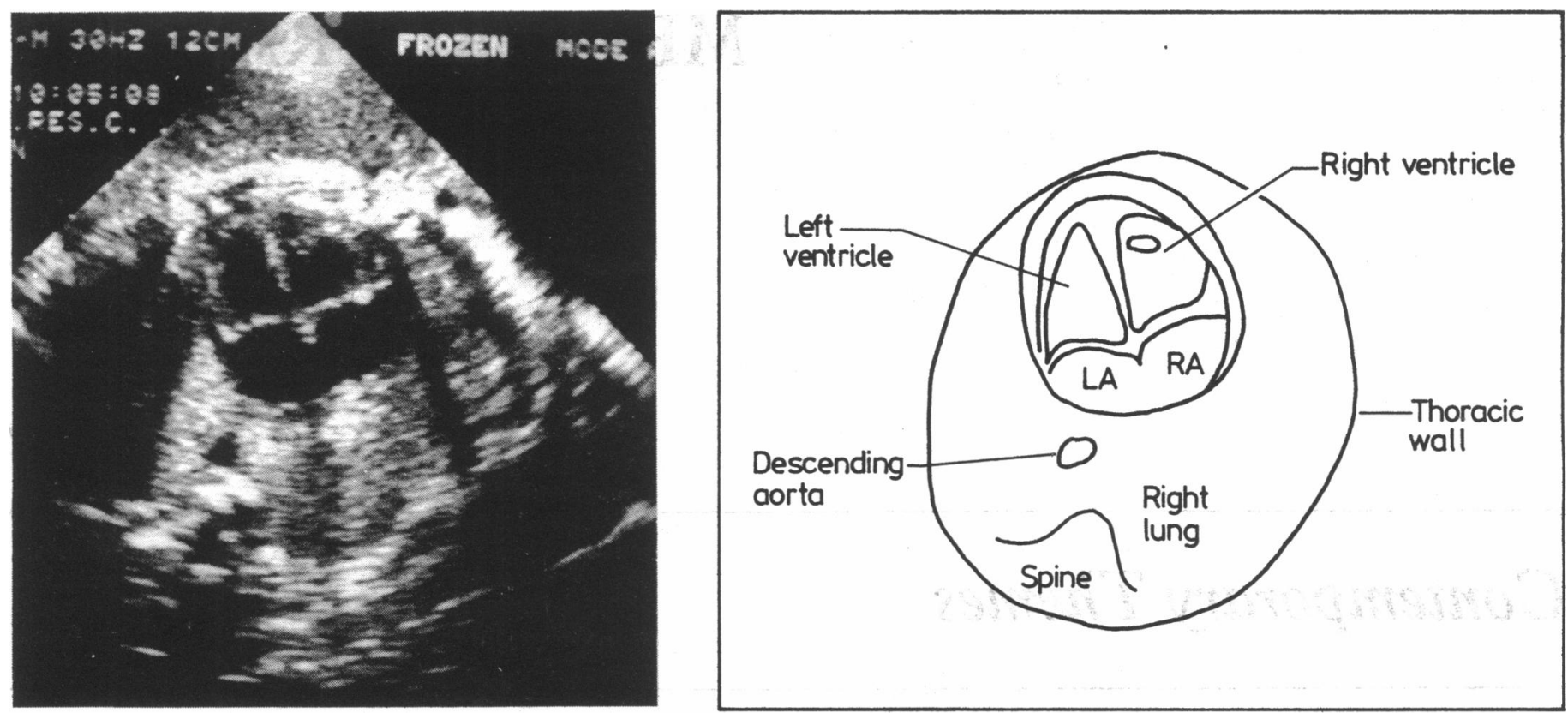

Four chamber view of fetal heart achieved by transecting fetal thorax with ultrasound beam horizontal at base of sternum. Spine is posterior; sternum lies opposite spine; right ventricle lies immediately below sternum. Descending aorta lies between left atrium and spine. Interventricular septum very thin just below atrioventricular valves and may show drop out in this projection. Septum will be seen to be intact in moving image, however, or when imaging this part of ventricular septum in different projection. LA, RA = Left atrium, right atrium.

TABLE I-Cases of congenital heart disease detected prenatally in referral centre and proportions suspected by referring ultrasonographers (Fanuary 1980 to October 1985)

\begin{tabular}{lccccccc}
\hline & 1980 & 81 & 82 & 83 & 84 & 85 & Total \\
\hline No detected in referral centre & 3 & 10 & 7 & 13 & 24 & 32 & 89 \\
No suspected before referral & & & 3 & 4 & 11 & 22 & 40
\end{tabular}

heart disease, or with maternal diabetes, or after exposure to cardiac teratogens in early pregnancy, or after finding an arrhythmia, non-immune hydrops, or extracardiac anomaly in the fetus. The fall in detection of abnormalities in 1982 was associated with the echocardiography centre being transferred from a general ultrasound obstetric referral unit to a centre of paediatric cardiology, where it was thought that the unit would be better placed. The proportion of affected pregnancies, however, changed from one in 50 in 1980 to a current rate of one in 12 referred to us.

Abnormality of the four chamber view was suspected by the referring ultrasonographer in four of 13 abnormalities detected in 1983, 11 of 24 detected in 1984, and 22 of 32 detected in the first nine months of 1985. Conversely, when a patient was referred with a suspected diagnosis of abnormality of the four chamber view congenital heart disease was confirmed in over $80 \%$ of cases.

\section{Discussion}

Our results are important on three counts. Firstly, they show that including examination of one section of the fetal heart in obstetric screening is feasible; secondly, that abnormality in this view can readily be distinguished from normal; and, thirdly, that fetal heart screening is already operating on a limited basis. Over $80 \%$ of the pregnant population in England receive at least one scan. ${ }^{8}$

Elective scanning for pregnancy dating is usually done at between 16 and 20 weeks of gestation, which is an ideal time to examine the fetal heart. At present many affected fetuses are not detected until late in pregnancy. An abnormality of pregnancy may develop-for example, fetal hydrops - which leads to a scan, and not until then is cardiac abnormality suspected by the obstetrician. Early detection of congenital heart disease, before 20 weeks, would allow patients to be referred for fetal echocardiography at a stage when various options are open. Termination of pregnancy can be discussed if the cardiac lesion has a poor prognosis. The abnormalities detectable by a four chamber view alone include hypoplastic left heart syndrome; mitral, pulmonary, or tricuspid atresia; and double inlet ventricle. Hypoplastic left heart syndrome is universally fatal but the prognosis of the others varies with the anatomical features." Also local surgical results affect the prognosis. The pioneers of the Fontan operation for tricuspid atresia quote an $80 \%$ success rate, but that was in selected patients; most units have less impressive results. ${ }^{1011}$

An important feature in antenatal counselling concerns the prospects for long term survival. Unfortunately, however, these are still unknown, since surgery for most of the defects likely to be seen has been available for only 15 years at most. Nevertheless, parents can make an informed decision at an early stage in pregnancy. Table II shows the outcome of pregnancy in the first 110 cases of predicted congenital heart disease. Of 57 patients diagnosed before 24 weeks of gestation, 48 chose termination because of multiple anomalies or the severity of heart disease. The high mortality in the remaining 53 cases is evidence that the sort of gross anomaly readily seen by obstetric scanners is usually associated with a poor prognosis; also those presenting with evidence of cardiac failure prenatally (nonimmune hydrops fetalis) commonly lose their fetuses in utero.

TABLE II-Outcome in 110 cases of congenital heart disease predicted prenatally (February 1980 to February 1986)

\begin{tabular}{lcccccc}
\hline & $\begin{array}{c}\text { Termination } \\
\text { of preg- } \\
\text { nancy }\end{array}$ & $\begin{array}{c}\text { Death } \\
\text { in } \\
\text { utero }\end{array}$ & $\begin{array}{c}\text { Neonatal } \\
\text { death }\end{array}$ & Alive & Total \\
\hline All cases & 47 & 23 & 30 & 10 & 110 \\
No with multiple anomalies & 25 & 8 & 7 & $3^{\star}$ & 43 \\
\hline
\end{tabular}

*Two babies had Down's syndrome.

Earlier diagnosis in these cases by means of a screening programme would allow more parents to have the option of termination for multiple abnormalities or those conditions associated with a poor prognosis. If the pregnancy continues the parents can be prepared for the problem and the likely postnatal events consequent on the defect. Transferring antenatal care to a centre with paediatric cardiac facilities is often indicated when the neonate is likely to need specialised emergency care or when interventional procedures are appropriate. Intrauterine rather than postnatal transfer ensures an infant in optimum condition for surgery and should reduce early 
morbidity and mortality - though, for reasons given above, this is not supported by our results.

Roughly three cardiac abnormalities per 1000 live births present in infancy, according to the New England regional infant care programme and a similar, more recent report from the Brompton Hospital. ${ }^{12}{ }^{13}$ Examination of the forms of congenital heart disease reported by these surveys suggests an anticipated detection rate of two abnormalities per 1000 by evaluation of the four chamber view alone. A screening programme would not detect all congenital heart disease but should detect over $60 \%$ of severe structural heart disease that presents in the first year of life.

We believe that extension and organisation of teaching is now warranted. This would not necessitate a change in resources or personnel at the peripheral level. Such a programme has recently been reported from France (L Fermont $e t$ al, paper delivered to the Second World Congress of Pediatric Cardiology, New York, 1985). In that study obstetricians were taught to recognise the four chamber view. In two years 20000 pregnancies were screened with the detection of 39 structural cardiac abnormalities. This represents a detection rate of two abnormalities per 1000 pregnancies. Our experience suggests that such a screening programme would not result in larger numbers of anxious patients being needlessly referred for a second opinion, as in nearly all of our referrals for "suspected congenital heart disease" the condition was confirmed. Even the figure from the French study of $10 \%$ positivity is acceptable, as reassurance may authoritatively be given by the specialist centre. False positive results by the referral centre should be extremely uncommon. In a series of 2500 patients seen by us over six years no major false positive prediction was made.

A prenatal cardiac screening programme would have profound implications for the practice and organisation of paediatric cardiology in the future if it became widespread. Close cooperation with an obstetric unit, preferably in the same hospital as the paediatric cardiology centre, and skill in fetal echocardiography would become an essential part of the paediatric cardiology service.
In summary, prenatal cardiac screening is already in progress and could simply be extended by an organised teaching drive. The far reaching implications of such a programme, however, should not be overlooked.

We thank all cooperating obstetric units, King's College Hospital ultrasound unit in particular, and the British Heart Foundation for support to LDA, DCC, and SKC.

\section{References}

1 Forfar JO, Arneil GC, eds. Demography, vital statistics and the pattern of disease in childhood. In: Texibook of paediatrics. 2nd ed. Edinburgh. Churchill Livingstone, 1978:24.

2 Keith JD, Rowe RD, Vlad P. Heart disease in infancy and childhood. 3rd ed. New York: Macmillan Publishing Co Inc, 1978:9.

3 Kleinman CS, Donnerstein RL, Devore GT, et al. Fetal echocardiography for evaluation of in utero congestive heart failure. $N$ Engl 7 Med 1982;10:568-75

4 Allan LD, Crawford DC, Anderson RH, Tynan MJ. Echocardiographic and anatomical correlate in fetal congenital heart disease. Br Heart $\mathcal{O} 1984 ; 52: 542-8$.

5 Stark J, Smallhorn H, Huhta J, et al. Surgery for congenital heart defects diagnosed with crosssectional echocardiography. Circulation 1983;68(suppl II): 129-34.

6 Rice MJ, Seward JB, Hagler DJ, et al. Impact of two-dimensional echocardiography on the management of distressed newborns in whom cardiac disease is suspected. Am f Cardiol 1983;51:288-95.

7 Allan LD, Tynan MJ, Campbell S, Wilkinson JL, Anderson RH. Echocardiographic and anatomical correlates in the fetus. Br Heart $\mathrm{f} 1980 ; 44: 445-51$.

Royal College of Obstetrics and Gynaecology Working Party on Routine Ultrasound Examination in Pregnancy. Report. London: RCOG $1984: 24$.

in Pregnancy. Report. London: RCOG, 1984:24.
de Brux JL, Zannini L, Binet JP, et al. Tricuspid atresia. Results of treatment in 115 children 7 Thorac Cardiovasc Surg 1983;85:440-6.

10 Fontan F, Deville C, Quaegebeur J, et al. Repair of tricuspid atresia in 100 patients. 7 Thorac Cardiovasc Surg 1983;85:647-60.

11 Miller RA, Seratto M. Long term evaluation of the Fontan operation for tricuspid atresia. In Syamasundar Rao P, ed. Tricuspid atresia. New York: Futura Press, 1982:293-307.

12 Fyler DC, Buckley LP, Hellenbrand WE, Cohn HE. Report of the New England regional infan care program. Pediatrics 1980;65:375-461.

13 Scott DJ, Rigby ML, Miller GAH, Shinebourne EA. The presentation of symptomatic hear disease in infancy based on 10 years' experience (1973-1982). Implications for the provision of services. Br Heart f 1984;52:248-57.

(Accepted 16 April 1986)

\title{
Nursing dependency in registered nursing homes and long term care geriatric wards in Edinburgh
}

\author{
ANN E CAPEWELL， WILLIAM R PRIMROSE， CELIA MACINTYRE
}

\begin{abstract}
There has been growing interest and public investment in registered nursing homes, apparently based on the assumption that these homes are the private equivalent of hospital long term care. We have tested this hypothesis in a survey comparing $\mathbf{4 0 0}$ patients in 18 registered nursing homes with 217 patients in 11 geriatric long term care wards in Edinburgh. The nursing home patients formed a distinct and separate group: $362(92 \%)$ were women, $392(98 \%)$ were single or widowed, and $358(90 \%)$ were
\end{abstract}

\section{Longmore Hospital, Edinburgh EH9 1S}

ANN E CAPEWELL, BS, MRCP, senior registrar in geriatric medicine

Eastern General Hospital, Edinburgh

WILLIAM R PRIMROSE, MRCGP, MRCP, senior registrar in general and geriatric medicine

Medical Computing and Statistics Unit, University of Edinburgh CELIA MACINTYRE, MSC, medical statistician

Correspondence to: Dr Capewell. self financing, whereas in the geriatric long term care group 148 $(68 \%)$ were women and $35(16 \%)$ were still married. Patients in nursing homes were also far less dependent than those in geriatric long term care wards $(p<0.005)$.

This study suggests that there may be large differences between the patients in these two types of institution, particularly with regard to nursing dependency. This finding has important implications in the future planning of long term places for the dependent elderly.

\section{Introduction}

During the past five years there has been a $21 \%$ increase in the number of registered nursing homes catering for medical, geriatric, and convalescent patients. ${ }^{1}$ The changes in the amount of financial help available from the Department of Health and Social Security and, in particular, the large rise in November 1983 have contributed to this growth ${ }^{2}$; it has also been encouraged politically by an official emphasis on exploring the wider use of the private and voluntary sector. ${ }^{3}$ This increase in the number of registered nursing homes has stimulated intense debate concerning their role in the overall 